\title{
Aerosol Deposition and Behavior on Leaves in Cool-temperate Deciduous Forests. Part 1: A Preliminary Study of the Effect of Fog Deposition on Behavior of Particles Deposited on the Leaf Surfaces by Microscopic Observation and Leaf-washing Technique
}

\author{
Yoko Watanabe*, Takashi Yamaguchi ${ }^{1)}$, Genki Katata ${ }^{2)}$ and Izumi Noguchi ${ }^{1)}$ \\ Field Science Center for Northern Biosphere, Hokkaido University, Sapporo 060-0809, Japan \\ ${ }^{1)}$ Institute of Environmental Sciences, Hokkaido Research Organization, Sapporo 060-0819, Japan \\ ${ }^{2)}$ Japan Atomic Energy Agency, Tokai-mura, Naka-gun, Ibaraki 319-1195, Japan
}

*Corresponding author. Tel: +81-11-706-3653, E-mail: youko@for.agr.hokudai.ac.jp

\begin{abstract}
To establish the method for investigating the behavior of aerosol particles deposited on the leaf surface against fog water under natural conditions, scanning electron microscopy with energy-dispersive X-ray (SEM-EDX) analysis and wash water analysis by ion chromatography after the washing treatment were performed using leaves of white birch collected from low part of the tree crown and the top of the tree in Sapporo City, Hokkaido, northern Japan. Each of collected leaves was divided into two parts according to the treatment performed: leaf surface (adaxial side) was 1) untreated, and 2) washed with deionized water with a pipette. In untreated samples, many particles of various shapes, including soil particles and organic debris, were deposited on the surface. Particles containing $\mathrm{S}$ were found on the surface of samples collected from only low part of the tree crown. After the washing treatment, SEM-EDX analysis revealed that soil particles and particles containing $S$ had been washed off with water, although some particles such as soil particles and organic debris still remained on the leaf surface. The major anion such as $\mathrm{SO}_{4}{ }^{2-}$ was detected in wash water of all samples, although the peak of S in X-ray spectra was not detected from samples collected at top of the tree. The combination of SEM-EDX analysis with wash water analysis indicated that $\mathrm{SO}_{4}{ }^{2-}$ was deposited on the leaf surface in dissolved state and/or in state of submicron particles. These results suggested that fog water could remove soil particles and particles containing $\mathrm{S}$ and $\mathrm{SO}_{4}{ }^{2-}$ from the leaf surfaces, but not all particles. There was no difference in sampling position in the tree crown. Our study suggested that com-
\end{abstract}

bination with SEM-EDX analysis and wash water analysis would be effective for investigation of the behavior of particles on the leaf surface against fog water.

Key words: Aerosol particles, Birch leaves, SEM-EDX, Cleaning technique

\section{INTRODUCTION}

Recently, the effect of aerosols on forest trees has been focused on because of an increase in transboundary air pollution from the Eurasian continent in parallel with promoting economic growth in Asian countries. Although several attempts have been made to estimate aerosol deposition fluxes in the forests of Japan using such as aerodynamic gradient method (e.g., Matsuda et al., 2010), there is little information on the direct effect of aerosols on forest trees in the field (Igawa and Okochi, 2009). On the other hand, many studies have revealed the direct effect of aerosols on physiological traits of tree seedlings after exposure of aerosols in growth chamber (Günthardt-Goerg and Vollenweider, 2007). However, it would be not always sufficient to apply these results to trees in the forest, because various environmental factors such as temperature, precipitation and herbivory as well as aerosol deposition affect the growth of forest trees. Therefore, we must consider both factors, i.e., estimation of aerosol deposition and effect of aerosols on physiological traits of trees for risk management of transboundary aerosol deposition in forests of Japan.

One way of assessing the direct effect of air pollu- 
tion on forest trees in relation with estimation of aerosol deposition is through leaf investigation. Plant leaves, in particular the leaves of perennial plants such as trees and shrubs, capture various atmospheric particles on their surface for long periods (Lorenzini et al., 2006; Tomasevic et al., 2005). Some studies reported that tree leaves were useful as passive samplers for monitoring air quality (Urbat et al., 2004; Shima et al., 1993).

Aerosol particles deposited on the leaf surface show various behaviors under natural conditions and affect the physiological traits of trees. These particles are dissolved by rain, fog, and dew (Lindberg et al., 1982). Some particles are removed from leaf surface by rain, but another remains on the leaf surface (Rossini Oliva and Raitio, 2003; Markert, 1995). Dissolved aerosol particles deposited on the leaf surfaces might penetrate to inside of leaves through cuticular layer and/or stomata, resulting in detrimental effects on plants, such as reduced photosynthesis and enhanced transpiration (Burkhardt, 2010). Also, some studies suggested that aerosol particles were responsible for erosion of epicuticular wax on the leaf surface (Igawa and Okochi, 2009; Sase et al., 1998; Turunen et al., 1990). Deliquescence of hygroscopic aerosol particles in high humid environments is also known (Burkhardt, 2010; Ebert et al., 2002). Burkhardt (2010) suggested that deliquescence of hygroscopic particles deposited on the leaf surface would influence epicuticular wax, resulting in water stress in plants. Thus, aerosol particles deposited on the leaf surfaces in the field would be sensitive to environmental conditions and change in physiological traits of trees might depend on the behavior of aerosol particles on the leaf surface under various environmental conditions. Therefore, to clarify the effect of aerosols on forest trees and to estimate aerosol deposition amount in view of the behavior of aerosol particles on the leaf surface, it is important to establish the methods for investigating the behavior of aerosols on leaf surfaces against rain and fog water.

The most common method for investigating the behavior of aerosols on leaf surfaces against rain and fog water is to wash the leaf surfaces experimentally by some kinds of solvents. Many cleaning techniques of foliar samples have been tried by using some solvents such as deiozined water and other solvents as well as some mechanical cleaning such as stripping and wiping with a cloth (Rossini Oliva and Raitio, 2003; Markert, 1995). Rossini Oliva and Raitio (2003) summarized the best cleaning procedure for foliar samples of tree species and showed that many studies recommended distilled water or deionized water to distinguish external from internal tissue composition in the case of broadleaf species, because water such as distilled water is the most effective, safe and cost efficient agent.
However, no one has focused on the behavior of aerosol particles on the leaf surfaces after cleaning treatments.

Another method for investigating the behavior of aerosols on leaf surfaces against rain and fog water is to observe aerosols on the leaf traits by scanning electron microscopy (SEM) before and after the washing treatment. SEM-EDX is a useful tool to observe particles and to analyze the elements of them on leaf surface (Tomasevic et al., 2005; Urbat et al., 2004). However, SEM-EDX analysis cannot detect particles in dissolved state on the leaf surface. Therefore, to achieve our goal, we investigated behavior of particles deposited on the leaf surface using the SEM-EDX technique in combination with the wash water analysis.

\section{MATERIALS AND METHODS}

\subsection{Site Description and Collection of Leaf Samples}

We took leaf samples at the following two areas located in Sapporo City $\left(43^{\circ} 06^{\prime} \mathrm{N}, 141^{\circ} 20^{\prime} \mathrm{E}\right)$ in Japan to estimate the wash effect of aerosol particles from leaf surface distinctly.

We selected white birch trees (Betula platyphylla Sukaczev var. japonica), because white birch is one of the representative species in cool temperate forests in Hokkaido. To collect leaves from low part of the tree crown, we selected garden trees grown in a row stretching east to west along the border of the area of Hokkaido Institute of Environmental Science located in urban area. Mean canopy height was about $20 \mathrm{~m}$. We selected one of them and took leaves at least three leaves from outer part of south-facing tree crown at about $2 \mathrm{~m}$ in height on 21 September 2011.

We selected a forest tree grown in the experimental forest (area; 146.77 ha) of Hokkaido Research Center, Forestry and Forest Products Research Institute, which is located $10 \mathrm{~km}$ away from Hokkaido Institute of Environmental Science. This area is a typical cool temperate forest in Hokkaido. The dominant canopy tree species are white birch (Betula platyphylla), oak (Quercus mongolica), maple (Acer mono) and Kalopanax septemlobus. Leaves of white birch were taken from top of the tree by climbing canopy tower at about 25 $\mathrm{m}$ height. We took at least three leaves from each part of tree crown without touching leaf surfaces on 21 September 2011. Before sampling, it was raining on 18 September 2011 (precipitation; $8 \mathrm{~mm}$ ). Then, it was cloudy from September 19 to 21. Collected leaves were fixed in Petri dishes without disruption of the leaf surface. 


\section{2 Washing Treatment of Leaves}

To simulate particle washing by rain and fog water, we used deionized water as a solvent for washing treatment according to Rossini Oliva and Raitio (2003). To avoid the leaching of some compositions from internal tissue of leaves by the washing treatment and to get wash water at relevant concentration for ion chromatography after the washing treatment, we did washing treatment with a small amount of water $(10 \mathrm{~mL})$ at short times (10 seconds).

Before air drying, each leaf was divided into two parts according to the type of treatment performed: leaf surface (adaxial side) was 1) untreated, and 2) washed with $10 \mathrm{~mL}$ deionized water for 10 seconds. At the washing treatment, samples were inclined at a thirty degree angle approximately with tweezers and then 5 $\mathrm{mL}$ deionized water was poured into leaf surface (adaxial side) gently using a pipette for 5 seconds once. We did this manipulation twice and collected total wash water. After this treatment, samples were fixed and air-dried in Petri dishes.

\section{3 SEM-EDX analysis}

Two air-dried specimen were obtained from the part near the midrib region of each leaf from each treatment group and stuck onto specimen stubs with carbon tape and then coated with carbon. Before carbon coating, dusts were blown off well by using a blower. Particles that were not blown off were recognized as particles deposited on the leaf surface. Particles with about $1 \mu \mathrm{m}$ in diameter or larger on the adaxial side of the leaf surfaces were observed in all samples and elements of particles were analyzed using SEM-EDX (JSM-6610 LA, JEOL, Tokyo, Japan) at an accelerating voltage of $10-15 \mathrm{kV}$. The working distance was $10 \mathrm{~mm}$. Total observation areas were about $0.28 \mathrm{~mm}^{2}$ in each sample and X-ray spectra of these observed areas were collected. Elements ( $\mathrm{Na}, \mathrm{Mg}, \mathrm{Al}, \mathrm{Si}, \mathrm{S}, \mathrm{K}, \mathrm{Ca}$ and $\mathrm{Fe}$ ) of each particle in the observed area were detected by EDX analysis and elemental mapping images of each particle in the observed area were taken. The intensity of the peaks in the EDX is not quantitative, but we compared relative peak height of each element before and after the washing treatment (Kutchko and Kim, 2006).

\subsection{Wash Water Analysis}

After the washing treatment, wash water was filter-
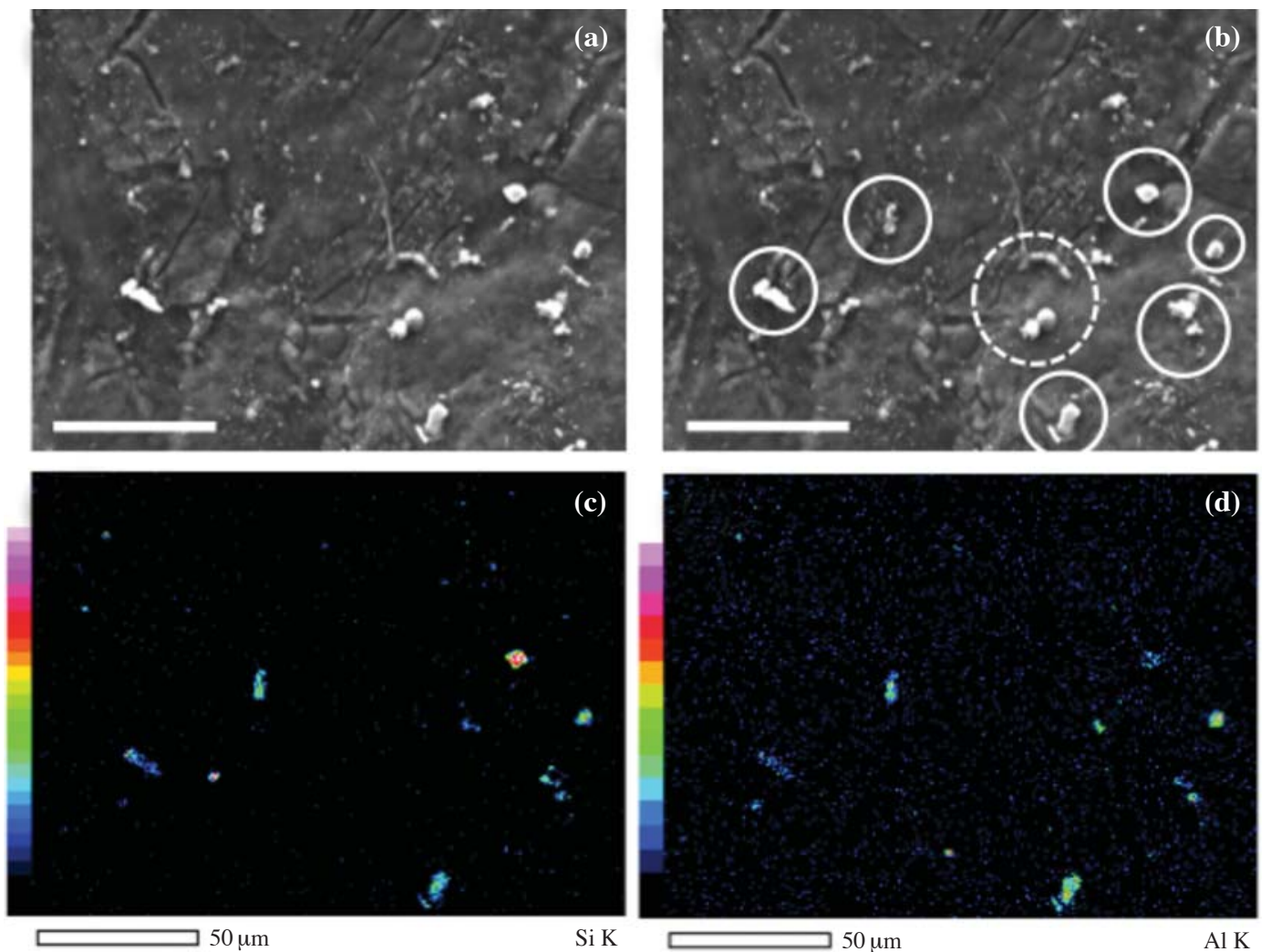

Fig. 1. SEM micrographs (a, b) and elemental mapping (c, d) of particles deposited on the surfaces of untreated white birch leaves collected at top of the tree. (a) Particles on the leaf surface; (b) same micrographs as in (a)-open circles show soil particles, and an open circle with dotted line shows particles such as organic debris; (c) silicon; (d) aluminum. Scale $=50 \mu \mathrm{m}$. 
ed through $0.2 \mu \mathrm{m}$ pore size filters (DISMIC-13C, ADVANTEC-Toyo, Tokyo, Japan) and the concentration of the major anion such as $\mathrm{SO}_{4}{ }^{2-}$ was measured by ion chromatography (Dionex ICS-2000, Dionex, Osaka, Japan). An IonPac AG17 $(4 \mathrm{~mm} \times 50 \mathrm{~mm})$ guard column and an IonPac AS17-C $(4 \mathrm{~mm} \times 250 \mathrm{~mm})$ analytical column were used. Before starting the conductivity detector, an ASRS-Ultra (4 mm) suppressor was connected. $\mathrm{SO}_{4}{ }^{2-}$ is the major component of aerosol particles in Hokkaido (Environmental Laboratories Association, 2012) and it is possible that $\mathrm{SO}_{4}{ }^{2-}$ deposition has occurred onto surfaces of tree leaves. Furthermore, $\mathrm{SO}_{4}{ }^{2-}$ analysis is considered to be effective for investigating the washing effect of aerosols on the leaf surface, because it has been reported that sulfate did not leach from inner tissues of leaves by throughfall (Garten et al., 1988). We calculated the area of each leaf after the washing treatment, and then the content of $\mathrm{SO}_{4}{ }^{2-}$ per $\mathrm{m}^{2}$ was calculated.

\section{RESULTS AND DISCUSSION}

We observed particles on the surfaces of white birch leaves in all samples by using SEM (Fig. 1a and $\mathrm{b}$ and Fig. 2a and c) and then, EDX analysis of observed areas was performed to obtain X-ray spectra (Fig. 2b and d). Elements of each particle in observed area were detected from mapping images of each element (Fig. 1c and d). Finally, we inferred what kinds of particles were deposited on leaf surface and what kinds of particles were removed after washing treatment. Table 1 showed the main elements detected by X-ray spectra and possible kind of particles. The result by ion chromatography was shown in Fig. 4.

\section{1 Untreated Leaf Samples}

In untreated samples from both low part of the crown and top of the tree, many particles of various shaped were observed on the leaf surface (Figs. 1a and 2a). Si and $\mathrm{Al}$ were detected in many particles in observed area by EDX analysis in all samples (Fig. 1c and d). In some particles, no elements except $\mathrm{C}$ and $\mathrm{O}$ were detected (Fig. 1b; an open circle with dotted line). These results showed that soil particles and organic debris and microorganisms such as bacteria were deposited on the leaf surfaces of white birch trees under natural conditions.
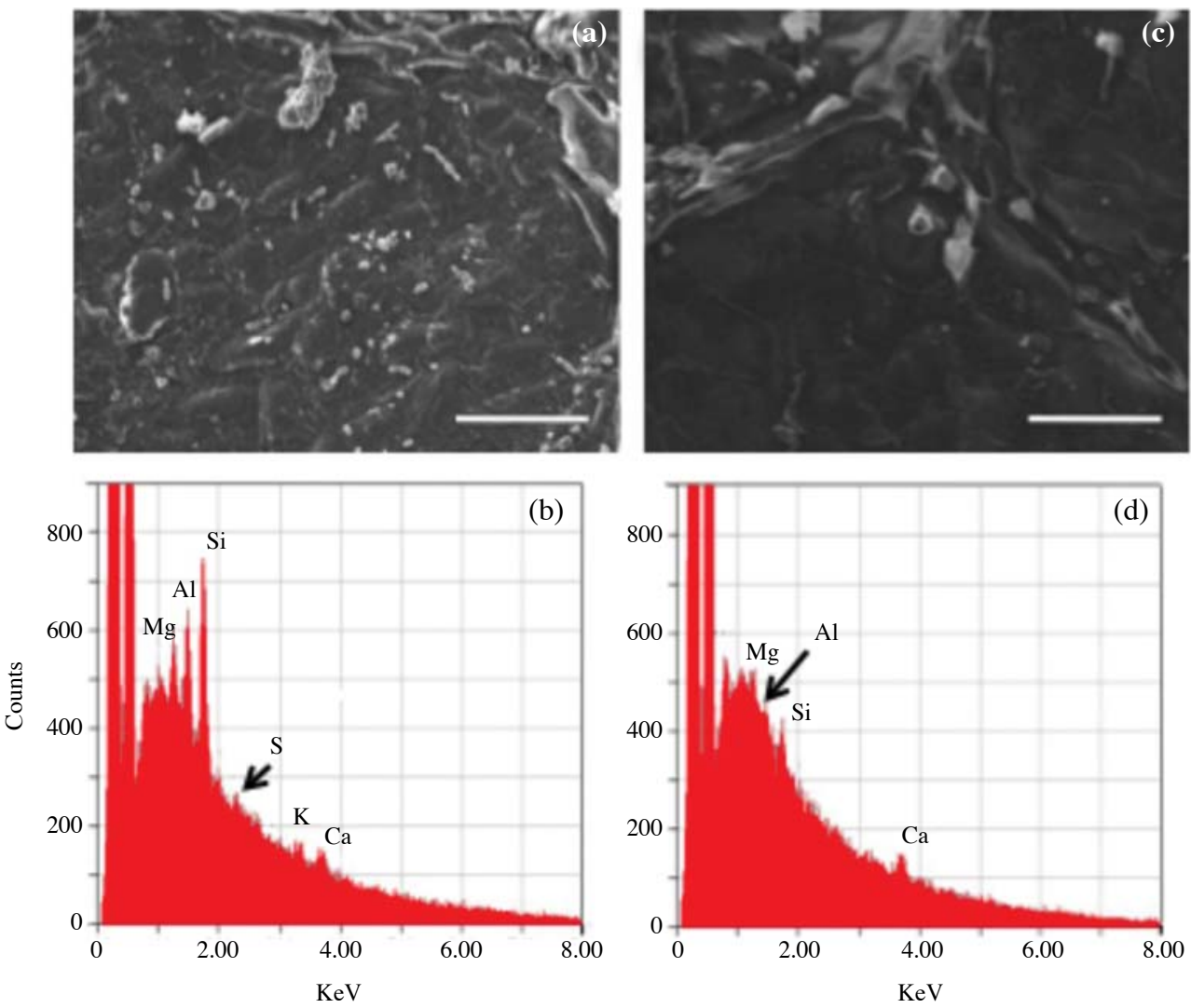

Fig. 2. SEM micrographs and X-ray spectra of observed area of white birch leaves collected from low part of the tree crown. (a, b) Untreated samples; (c, d) samples after the washing treatment. Scale $=50 \mu \mathrm{m}$. 
Table 1. The summary of the results from X-ray spectra of observed areas, possible particles from elements image mapping and the anions in wash water before and after washing treatment $(n=3)$.

\begin{tabular}{|c|c|c|c|c|}
\hline & \multicolumn{2}{|c|}{ Low part of tree crown } & \multicolumn{2}{|c|}{ Top of the tree } \\
\hline & Untreated & Washed & Untreated & Washed \\
\hline $\begin{array}{l}\text { Elements detected by } \\
\text { X-ray spectra }\end{array}$ & $\mathrm{Na}, \mathrm{Mg}, \mathrm{Al}, \mathrm{Si}, \mathrm{S}, \mathrm{K}, \mathrm{Ca}$ & $\mathrm{Mg}, \mathrm{Al}, \mathrm{Si}, \mathrm{Ca}$ & $\mathrm{Na}, \mathrm{Mg}, \mathrm{Al}, \mathrm{Si}, \mathrm{K}, \mathrm{Ca}$ & $\mathrm{Mg}, \mathrm{Al}, \mathrm{Si}, \mathrm{Ca}$ \\
\hline $\begin{array}{l}\text { Particles observed on } \\
\text { the leaf surface }\end{array}$ & $\begin{array}{l}\text { Soil, Particles including } \\
\text { S such as soil and } \mathrm{CaSO}_{4}\end{array}$ & Soil & Soil & Soil \\
\hline Anions in wash water & $\mathrm{SO}_{4}{ }^{2-}$ & Not detected & $\mathrm{SO}_{4}{ }^{2-}$ & Not detected \\
\hline
\end{tabular}
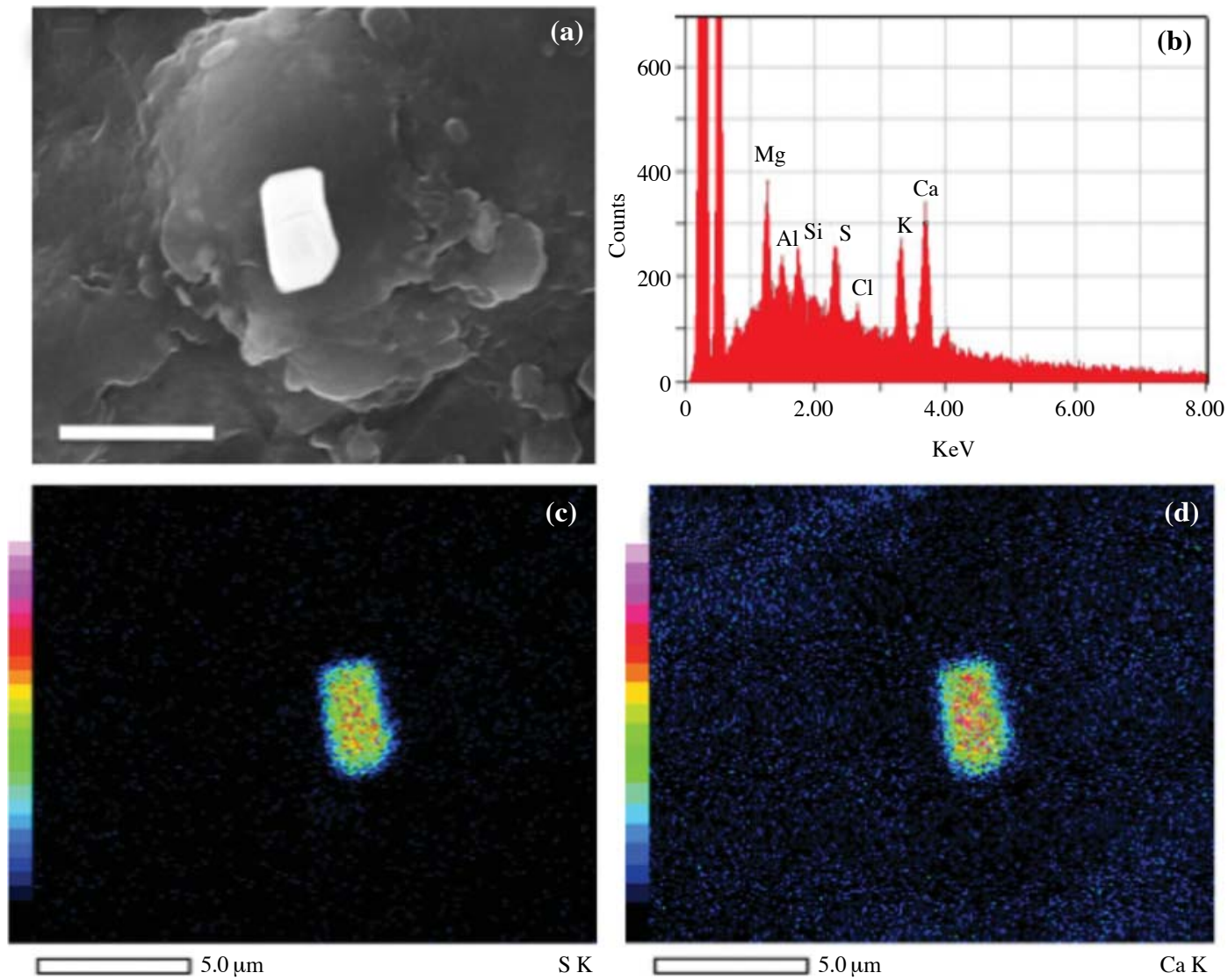

Fig. 3. SEM micrograph (a), X-ray spectrum (b) of observed area, and elemental mapping (c, d) of a particle on the leaf surface of untreated sample collected from low part of the tree crown. This particle contained S and Ca. Scale $=50 \mu \mathrm{m}$.

In untreated samples from low part of the tree crown, particles containing $\mathrm{S}$ were sometimes found (Fig. 3c). The size of these particles containing $\mathrm{S}$ was less than $5 \mu \mathrm{m}$ in diameter and of various shapes. X-ray spectra of observed areas exhibited strong peaks of $\mathrm{Si}$ and $\mathrm{S}$ in untreated samples (Fig. 2b). The particles containing $\mathrm{S}$ were considered to be soil particles and $\mathrm{CaSO}_{4}$ (Fig. 3 ). The particles might be originated from emissions of aerosols containing $\mathrm{S}$ from the ground surface (Urbat et al., 2004). On the other hand, we could not detect the peak of S in X-ray spectra in untreated samples at top of the tree. However, the content of $\mathrm{SO}_{4}{ }^{2-}$ per $\mathrm{m}^{2}$ (mean value $\pm \mathrm{SD}$ ) in wash water was $1.04 \pm 0.41 \mathrm{mg}$ per $\mathrm{m}^{2}$ in samples from low part of the tree crown and $1.00 \pm 0.64 \mathrm{mg}$ per $\mathrm{m}^{2}$ in samples at top of the tree, respectively (Fig. 4). This situation may be explained by that particulate $\mathrm{SO}_{4}{ }^{2-}$ deposited from the atmosphere deliquesced under high humid condition due to leaf transpiration (Burkhardt, 2010), because the major components of aerosol particles in Sapporo were $\left(\mathrm{NH}_{4}\right)_{2} \mathrm{SO}_{4}$ 


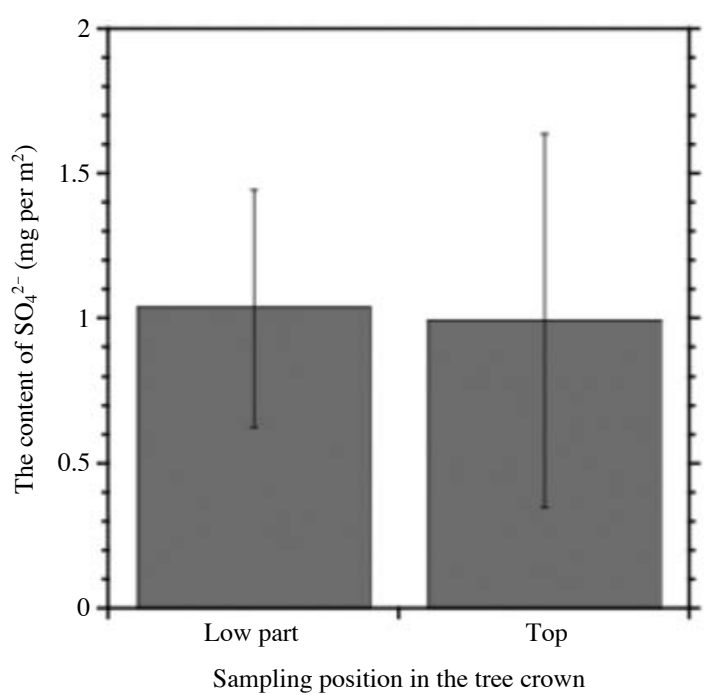

Figure 4. The content of $\mathrm{SO}_{4}{ }^{2-}$ per $\mathrm{m}^{2}(\mathrm{n}=3$, mean value \pm $\mathrm{SD})$ in wash water in samples from low part of the tree crown and top of the tree.

(Environmental Laboratories Association, 2012). As a result, the dissolved $\mathrm{SO}_{4}{ }^{2-}$ covered the leaf surface in samples of top of the tree. Also, it is possible that $\mathrm{SO}_{2}$ gas was converged to the particle form of $\mathrm{SO}_{4}{ }^{2-}$ in the atmosphere and deposition of these particles to leaf surface occurred. It is likely that SEM-EDX could not detect particulate $\mathrm{SO}_{4}{ }^{2-}$ at submicron level, because these particles were mainly smaller than $1 \mu \mathrm{m}$ in size (Kleeman and Cass, 1998). Our technique showed that the occurrence of deliquescence at high humid conditions on the top of tree was important in view of the behavior of aerosol particles deposited on the leaf surfaces.

\section{2 Treated Leaf Samples}

After the washing treatment, the peak of Si almost was smaller than that of untreated samples from low part of the tree crown and top of the tree (Fig. 2d), although EDX detected some particles containing $\mathrm{Si}$ and Al. SEM micrographs showed that many particles such as particles containing $\mathrm{Si}$ and particles which elements except $\mathrm{C}$ and $\mathrm{O}$ were not detected still remained on the leaf surface, irrespective of the washing treatment in all samples (Fig. 2c). These results showed that the washing treatment in this study did not wash off all particles from leaf surfaces and some particles remained on the surfaces after the treatment (Fig. 2c). It is likely that all particles such as soil particles and organic debris are not washed off by rainfall and fog water. This situation is considered to occur when the particles were attached in asperity of leaves.

The peak level of S also was not detected in all sam- ples after the washing treatment. Our study indicated that some types of particles such as soil and $\mathrm{CaSO}_{4}$ and the anion such as $\mathrm{SO}_{4}{ }^{2-}$ on leaf surfaces would be washed off by rainfall and fog water. Some studies have been reported that exposure of stimulated acid rain and acid mist containing sulfate caused visible injury of plant leaves (Günthardt-Goerg and Vollenweider, 2007). Therefore, deposition of aerosols containing sulfate such as $\left(\mathrm{NH}_{4}\right)_{2} \mathrm{SO}_{4}$ to cool temperate forests in Hokkaido might affect the leaf tissue of forest trees. However, it is possible that cleaning of the leaf surface by fog deposition would mitigate the effect of aerosols containing sulfate on forest trees.

Our study showed that SEM-EDX analysis could reveal the behavior of aerosol particles after washing treatment simulated fog deposition qualitatively, and wash water analysis by ion chromatography could detect the major anion on the leaf surface quantitatively. Combination with SEM-EDX analysis and wash water analysis would be effective for investigation of the behavior of particles on the leaf surface against fog water.

\section{ACKNOWLEDGEMENT}

We would like to thank Drs. A. Uemura and S. Kitaoka for collecting samples in Hokkaido Research Center, FFPRI, and Dr. K. Itabashi for his help with SEMEDX analysis. This work was supported by Grant-inAid for Scientific Research on Innovative Areas (211 20501, 23120701).

\section{REFERENCES}

Burkhardt, J. (2010) Hygroscopic particles on leaves: nutrients or desiccants? Ecological Monographs 80, 369399.

Ebert, M., Inerle-Hof, M., Weinbruch, S. (2002) Environmental scanning electraon microscopy as a new technique to determine the hygroscopic behavior of individual aerosol particles. Atmospheric Environment 36, 59095916.

Environmental Laboratories Association (2012) Acid deposition survey in Japan, Phase (2011). Journal of Environmental Laboratories Association 37, 2-50 (in Japanese).

Garten, C.T. Jr., Bondietti, E.A., Lomax, R.D. (1988) Contribution of foliar leaching and dry deposition to sulfate in net thoughfall below deciduous trees. Atmospheric Environment 22, 1425-1432.

Günthardt-Goerg, M., Vollenweider, P. (2007) Linking stress with macroscopic and microscopic leaf response in trees: New diagnostic perspectives. Environmental 
Pollution 147, 467-488.

Igawa, M., Okochi, H. (2009) Observation of atmospheric chemistry and effects of acid deposition on forest ecosystem in Mt. Oyama, Tanzawa Mountains. Journal of Aerosol Research, Japan 42, 97-104 (in Japanese with English summary).

Kleeman, M.J., Cass, G.R. (1998) Source Contributions to the size and composition distribution of urban particulate air pollution. Atmospheric Environment 32, 28032816.

Kutchko, B.B., Kim, A.G. (2006) Fly ash characterization by SEM-EDS. Fuel 85, 2537-2544.

Lindberg, S.E., Harris, R.C., Turner, R.R. (1982) Atmospheric deposition of metals to forest vegetation. Science 251, 1609-1611.

Lorenzini, G., Grassi, C., Nali, C., Petiti, A., Loppi, S., Tognotti, L. (2006) Leaves of Pittosporum tobira as indicators of airborne trace element and PM10 distribution in central Italy. Atmospheric Environment 40, 40254036.

Markert, B. (1995) Sample preparation (cleaning, drying, homogenization) for trace element analysis in plant materials. The Science of the Total Environment 176, 45-61.

Matsuda, K., Fujimura, Y., Hayashi, K., Takahashi, A., Nakaya, K. (2010) Deposition velocity of PM2.5 sulfate in the summer above a deciduous forest in central Japan. Atmospheric Environment 44, 4582-4587.
Rossini Oliva, S., Raitio, H. (2003) Review of cleaning techniques and their effects on the chemical composition of foliar samples. Boreal Environment Research 8, 263-272.

Sase, H., Takamatsu, T., Yoshida, T., Inubushi, K. (1998) Changes in properties of epicuticular wax and the related water loss in Japanese cedar (Cryptomeria japonica) affected by anthropogenic environmental factors. Canadian Journal of Forest Research 28, 546-556.

Shima, K., Matsuzaki, Y., Chiba, K. (1993) A study on capture of air-wafting heavy metal elements with leaves surface of suburban forest. Journal of the Japanese Society of Revegetation Technology 19, 1-10.

Tomasevic, M., Vukmirovic, Z., Rajsic, S., Tasic, M., Stevanovic, B. (2005) Characterization of trace metal particles deposited on some deciduous tree leaves in an urban area. Chemosphere 61, 753-760.

Turunen, M., Huttunen, S. (1990) A review of the response of epicuticular wax of conifer needles to air pollution. Journal of Environmental Quality 19, 35-45.

Urbat, M., Lehndorff, E., Schwark, L. (2004) Biomonitoring of air quality in the Cologne conurbation using pine needles as a passive sampler-Part I: magnetic properties. Atmospheric Environment 38, 3781-3792.

(Received 31 May 2012, revised 1 February 2013, accepted 4 February 2013) 